\title{
Material Aspects of Hot Rolling and Cooling Conditions for Strips from Martensitic Steel
}

\author{
Michal Dziedzic ${ }^{1, a^{*}}$, Stanislaw Turczyn ${ }^{1, b}, Z^{2}$ bigniew Kuzminski ${ }^{1, c}$ \\ ${ }^{1}$ AGH University of Science and Technology, Mickiewicza 30, Kraków, Poland \\ adziedzic@agh.edu.pl, bturczyn@metal.agh.edu.pl, 'kuzminsk@metal.agh.edu.pl
}

Keywords: martensitic steel, thermo-mechanical rolling, strip rolling.

\begin{abstract}
The paper focuses on experimental investigations of own designed, cast and then hot rolled martensitic steel. In order to understand the effect of the thermo-mechanical rolling parameters on the formation of the microstructure and resulting mechanical properties many tests and experiments have been performed. Martensitic steels offer satisfied balance of cost production, light weight and mechanical properties. These characteristics are achieved by using low alloy steel as a basis, and strict control of rolling conditions, strain rate, cooling rate and coiling temperature.
\end{abstract}

\section{Introduction}

Limiting energy consumption and air pollution play the key role in the weight reduction of car body construction. At the same time, high level of active and passive safety must be guaranteed or even increased. Such situation cause, that the material choice for auto body outer is a key decision. As a response of the automotive industry requirements martensitic steels have been developed by metallurgical industry. These steels belong to the group of Advanced High Strength Steels and now are widely investigated. Modern car design puts an increasing emphasis on the application of materials for automotive body outers, closures, suspensions and other components, which achieve specific engineering targets such as low vehicle mass, high passive safety, stiffness, fatigue, comfort, acoustics, corrosion and recycling [2]. Steel as a material is currently still used for car bodies, almost in $100 \%$ for passenger cars having a steel body, and around $60 \%$ of the car weight consisting of steel or steel based parts [6]. Automotive industry is looking also for light materials based on $\mathrm{Al}$ and $\mathrm{Mg}$ alloys to lower the car weight. However, steel industry has created innovative steel based solutions with close collaboration to automotive manufacturers by supporting them in their own developments. Such cooperation helped carmakers to develop the solution to increase passenger safety in the event of collision, and the most designed cars reach positive ratings in standardized crash FEA simulation specified by Euro NCAP and NHS demands. High impact energy absorption is demanded generally in front and rear impact tests, but anti injury passenger behavior is required for side impact and roll over situations. For this aspects, Advanced High Strength Steels (AHSS), which as well supports increased fuel economy are the steels of choice for automotive development activities [1]. The most common AHSS is the dual phase steel that consist of ferrite-martensite microstructure [3,4]. These steel is characterized by high strength, good ductility, low yield to tensile strength and high bake-hardenability. Another class of AHSS steels are multi phase steels which have a complex microstructure consisting of various phase constituents and high yield to tensile ratio [5]. Transformation Induced Plasticity, Complex Phase and Martensitic steels (MS) are the latest AHSS steels finding interests among automotive automakers $[4,5]$.

In the paper, current developments in the laboratory of hot rolled Martensitic Steel is briefly discussed. The experimental and numerical investigations of own designed, cast and then hot rolled martensitic steel are presented. In order to understand the effect of the thermo-mechanical rolling parameters on the formation of the microstructure and resulting mechanical properties many tests and experiments have been performed. 


\section{Thermomechanical Rolling}

One of the feasible tools to enhance the properties and to improve the quality of steel products is the thermomechanical rolling (TMR). TMR is the sophisticated combination of well defined deformation operations and heat treatment in a single production stage to control the microstructure of material. When such combination is properly realized, the product must satisfy the customer requirements. It must have desired dimensions, shape and surface quality and acceptable mechanical properties. From this point of view, TMR is generally considered as the final manufacturing stage in rolling mills.

\section{Tested Material}

The samples for tests were prepared from own cast of Martensitic Steel (MS), which was made in laboratory condition. Chemical composition of MS steel was designed according to the standard EN 10336, Table 1. In order to improve hardenability, it contains increased manganese and silicon content. Additionally, the steel contains $\mathrm{Nb}$ and Ti microalloys.

Table 1. Chemical composition of the investigated MS steel

\begin{tabular}{|c|c|c|c|c|c|c|c|c|c|c|c|}
\hline $\mathrm{C}$ & $\mathrm{Mn}$ & $\mathrm{Si}$ & $\mathrm{Cr}$ & $\mathrm{Ni}$ & $\mathrm{Mo}$ & $\mathrm{Al}$ & $\mathrm{Ti}$ & $\mathrm{Nb}$ & $\mathrm{V}$ & $\mathrm{B}$ & $\mathrm{N}$ \\
\hline 0.21 & 1.44 & 0.33 & 0.63 & 0.03 & 0.22 & 0.011 & 0.027 & 0.05 & 0.006 & 0.0002 & 0.007 \\
\hline
\end{tabular}

The melt was done in the vacuum induction furnace. Liquid metal was cast into ingot moulds using argon shield. Obtained ingot with the dimension of $180-220 \mathrm{~mm}$ in diameter and $1200 \mathrm{~mm}$ in length has weight of $100 \mathrm{~kg}$. It was subjected to open die forging in order to get flat bars, which have the dimensions $160 \times 60 \times 1300 \mathrm{~mm}^{3}$. Such pre-formed material was used for preparing all samples for further laboratory tests.

\section{CCT Diagram of Martensitic Steel}

Dilatometric tests were performed as the preliminary stage of the experiments. The tested samples of dimensions $ø 2 \times 12 \mathrm{~mm}$ was placed in the dilatometer DT 1000 of the Adamel Company and continuously heated to $1000{ }^{\circ} \mathrm{C}$ with a rate of $3{ }^{\circ} \mathrm{C} / \mathrm{s}$, and next cooled with the speed of $1{ }^{\circ} \mathrm{C}$ to the ambient temperature. During heating and cooling the relative elongation $\Delta \mathrm{L} / \mathrm{L}_{0}$ as the function of temperature was recorded. The kinetic of phase transformation of cooled austenite for tested martensitic steel was determined. Each measure written digitally was differentiated, what helped for precise definition of start and finish of particular transformation (Table 2). Realized testing was necessary for making up CCT diagram (Fig. 2). Metallographic sections were made on the heated and cooled samples by application of Axiovert 200 Matt Zeiss (multiplication 950x). The Vickers hardness (HV10) was measured on all heat treated and cooled samples using Vickers equipment type HPO 250. 


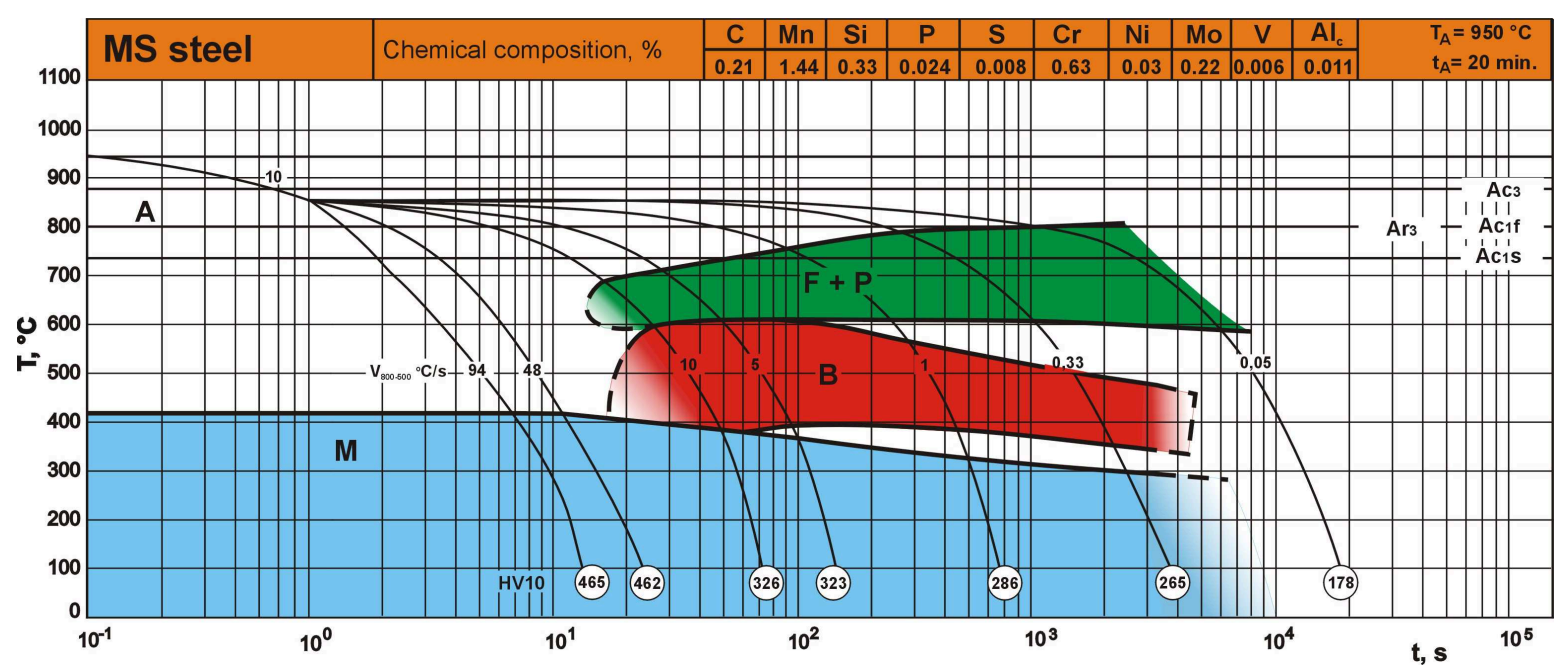

Fig. 1. CCT diagram of Martensitic Steel after austenitizing $\mathrm{T}_{\mathrm{A}}=950^{\circ} \mathrm{C}$
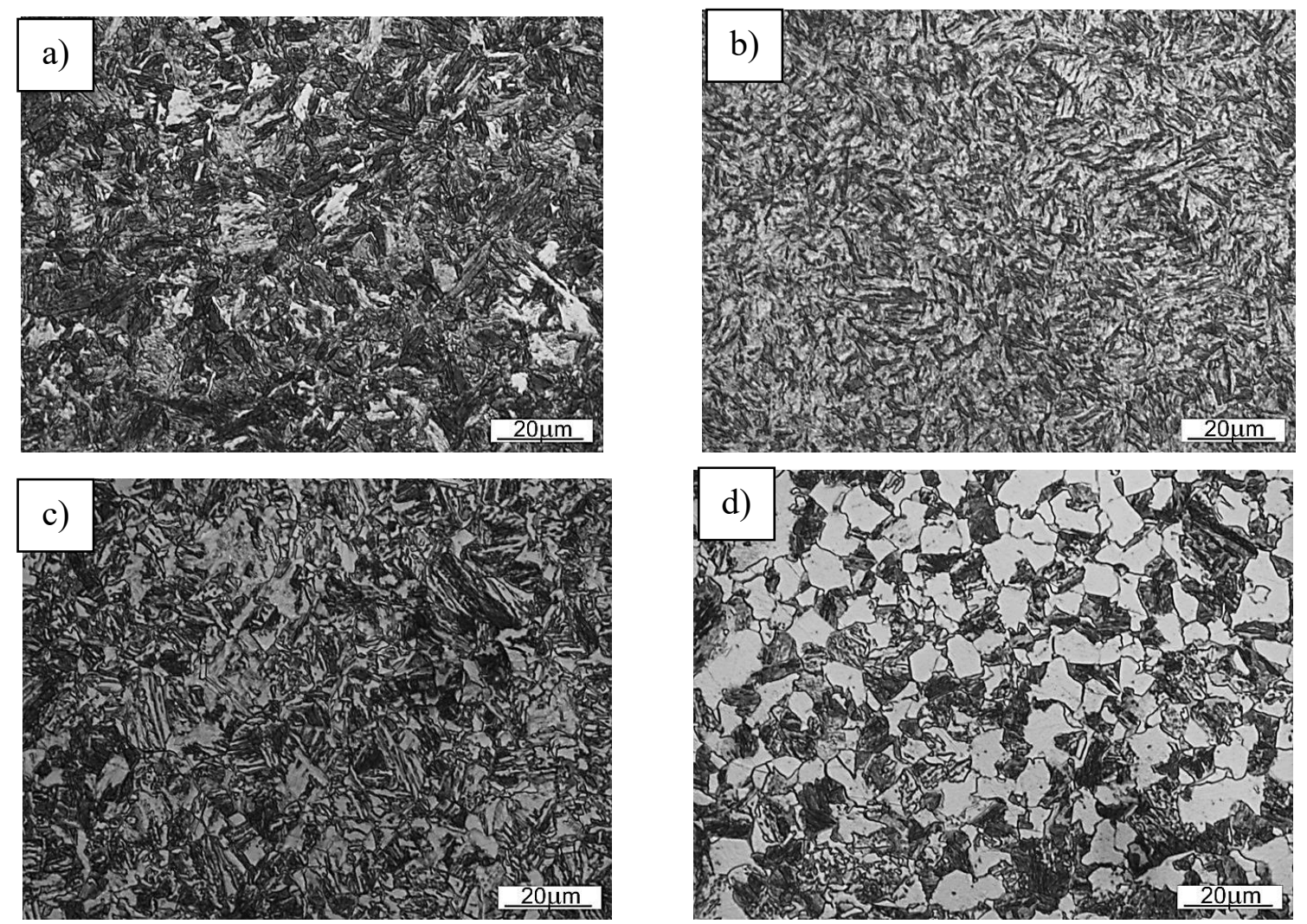

Fig. 2. The microstructure of chosen samples for martensitic steel cooled from $\mathrm{T}_{\mathrm{A}}=950{ }^{\circ} \mathrm{C}$ with different speed: a) $100{ }^{\circ} \mathrm{C} / \mathrm{s}$, b) $50{ }^{\circ} \mathrm{C} / \mathrm{s}$, c) $10^{\circ} \mathrm{C} / \mathrm{s}$ and d) $1{ }^{\circ} \mathrm{C} / \mathrm{s}$

Fig 1. presents CTT diagram for Martensitic Steel after austenitiing in the temperature $950{ }^{\circ} \mathrm{C}$. The researched steel characterizes very good tempering. Application of cooling speed higher than $50{ }^{\circ} \mathrm{C} / \mathrm{s}$ from the finish rolling temperature, designed for $890{ }^{\circ} \mathrm{C}$, has exceed critical cooling speed and has been received full martensitic microstructure, Fig. $2 \mathrm{a}$ and $2 \mathrm{~b}$. In the range of cooling speed 10 to $5{ }^{\circ} \mathrm{C} / \mathrm{s}$ in the observed microstructure exists ferrite and bainite (Fig. 2c), however for the application of lowest cooling rates perlite is also observed (Fig 2d). In the range of used cooling rates for previously astenitized steel at $950{ }^{\circ} \mathrm{C}$ the hardness decreases from $465 \mathrm{HV}\left(\mathrm{V}_{\text {cool }}=94{ }^{\circ} \mathrm{C} / \mathrm{s}\right)$ to $178 \mathrm{HV}\left(\mathrm{V}_{\text {cool }}=0.005^{\circ} \mathrm{C} / \mathrm{s}\right)$. 


\section{Plane Strain Compression Test}

To obtain valuable information about force and energetic parameters, which can appear during hot rolling of MS steel in the rolling mill, which has six stands in finishing group, plane strain compression test has been realized. Thermo-mechanical processing was carried out using multifunctional Gleeble HDS-V 40 simulator. The samples have been compressed under conditions similar to the plane state of strain. Ni-based lubricant was used in order to decrease the friction between the surface of the deformed sample and the surface of a die. The samples were subjected to six-steps of processing, for which the finishing temperature of hot deformation was equal $910{ }^{\circ} \mathrm{C}$ and the cooling conditions to the ambient temperature were designed basing on the CCT curves.

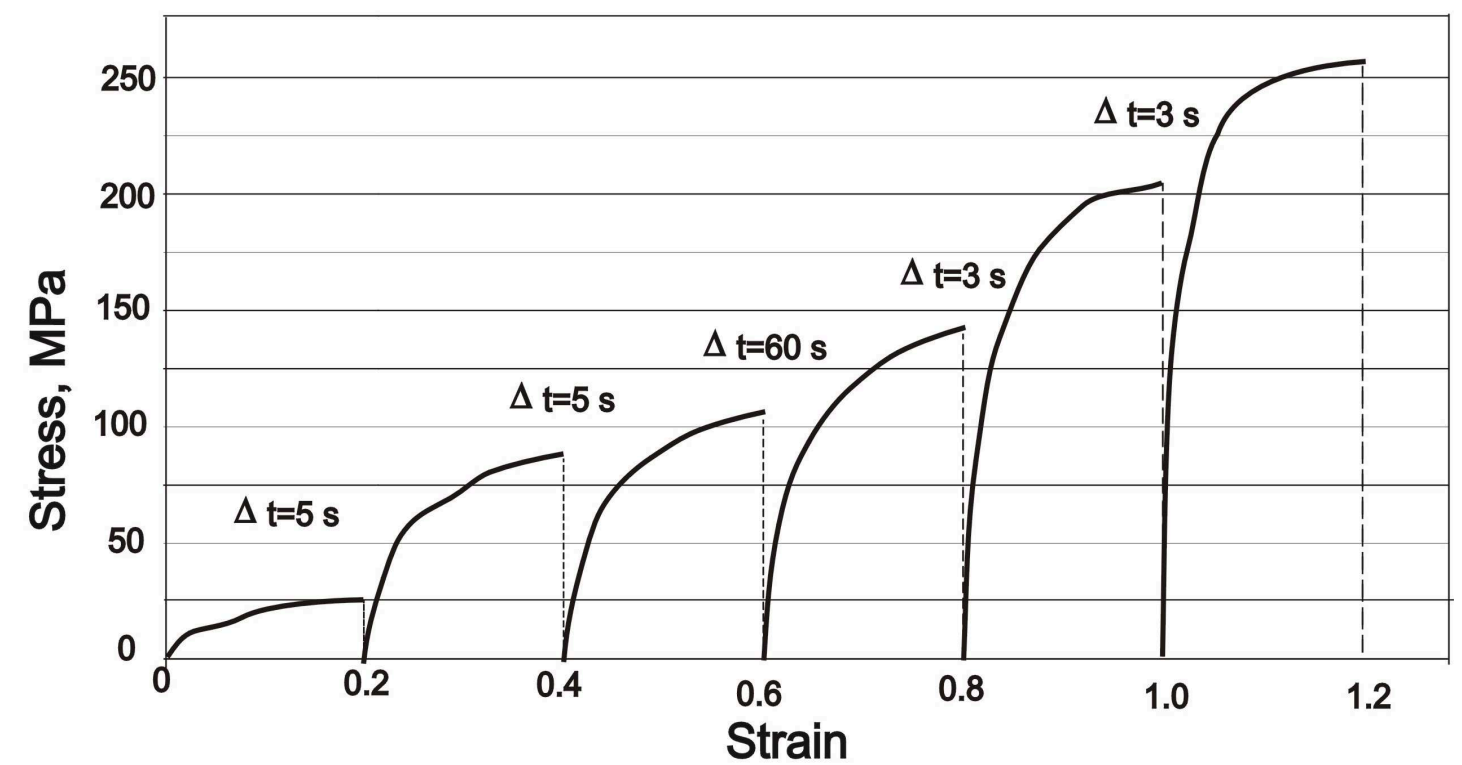

Fig. 3. Changes of stress as a function of strain for successive deformation stages within temperature range from $1125^{\circ} \mathrm{C}$ (first pass) to $910{ }^{\circ} \mathrm{C}$ (last pass).

As the result of the six-step deformation at the temperature range from $1125^{\circ} \mathrm{C}$ to $910{ }^{\circ} \mathrm{C}$ the stress-strain curves have been obtained, presented in Fig. 3. The stress values increase significantly with decreasing deformation temperature. The highest growth of stress occurs for deformation temperature at $910^{\circ} \mathrm{C}$, what is caused by existing the highest strain rate (around $10 \mathrm{~s}^{-1}$ ).

\section{Experimental Rolling of Martensitic Steel}

The samples of dimensions $12.4 \times 26.8 \times 120 \mathrm{~mm}$ were machined from hot forged slabs and then finally hot-rolled to various thickness steel samples. Four high rolling stand with rolls of $\varnothing 100 / 400$ $\mathrm{mm}$ was used for this purpose. After austenitizing at $1250{ }^{\circ} \mathrm{C}$ for $600 \mathrm{~s}$, the specimens were deformed in two passes for version $2 \mathrm{P}$ and in three passes for version 3P, mainly in the austenite region (Table 2). Final thickness was around $4.8 \mathrm{~mm}$ for version $2 \mathrm{P}$ and $3 \mathrm{P}$. During rolling has been controlled the interval between two/three deformation in order to attain finishing rolling temperature of around $910{ }^{\circ} \mathrm{C}$. After finishing rolling, specimens were cooled using different medium (water, water spray, air) to the ambient temperature. 
Table 2. Schedule of experimental rolling and controlled cooling of MS steel sample

\begin{tabular}{|c|c|c|c|c|c|}
\hline \multirow{2}{*}{ Series } & \multicolumn{4}{|c|}{ HOT ROLLING } & \multirow{2}{*}{$\begin{array}{c}\text { COOLING } \\
\text { Cooling way }\end{array}$} \\
\hline & $\begin{array}{l}\text { Heating } \\
\text { temp., }{ }^{\circ} \mathrm{C}\end{array}$ & $\begin{array}{l}\text { Roll end } \\
\text { temperature }\end{array}$ & $\begin{array}{l}\text { Number } \\
\text { of passes }\end{array}$ & $\begin{array}{c}\text { Reductions } \\
\text { in the passes, \% }\end{array}$ & \\
\hline $2 \mathrm{P}-\mathrm{A}$ & 1250 & above $\mathrm{Ar}_{3}$ & 2 & $1 \times 45+1 \times 30$ & water, rate $\sim 200^{\circ} \mathrm{C} / \mathrm{s}$ \\
\hline $2 \mathrm{P}-\mathrm{B}$ & 1250 & above $\mathrm{Ar}_{3}$ & 2 & $1 \times 45+1 \times 30$ & water sprinkling, rate $\sim 25^{\circ} \mathrm{C} / \mathrm{s}$ \\
\hline $2 \mathrm{P}-\mathrm{C}$ & 1250 & above $\mathrm{Ar}_{3}$ & 2 & $1 \times 45+1 \times 30$ & air, rate $\sim 1{ }^{\circ} \mathrm{C} / \mathrm{s}$ \\
\hline $3 P-D$ & 1250 & below $\mathrm{Ar}_{3}$ & 3 & $1 \times 30+2 \times 25$ & water, rate $\sim 200^{\circ} \mathrm{C} / \mathrm{s}$ \\
\hline $3 \mathrm{P}-\mathrm{E}$ & 1250 & below $\mathrm{Ar}_{3}$ & 3 & $1 \times 30+2 \times 25$ & water sprinkling, rate $\sim 25^{\circ} \mathrm{C} / \mathrm{s}$ \\
\hline $3 \mathrm{P}-\mathrm{F}$ & 1250 & below $\mathrm{Ar}_{3}$ & 3 & $1 \times 30+2 \times 25$ & air, rate $\sim 1{ }^{\circ} \mathrm{C} / \mathrm{s}$ \\
\hline
\end{tabular}

\section{Results and Discussion}

An essential element of carried out investigation was to determine an effect of the rolling and cooling conditions on the microstructure and mechanical properties of tested material.
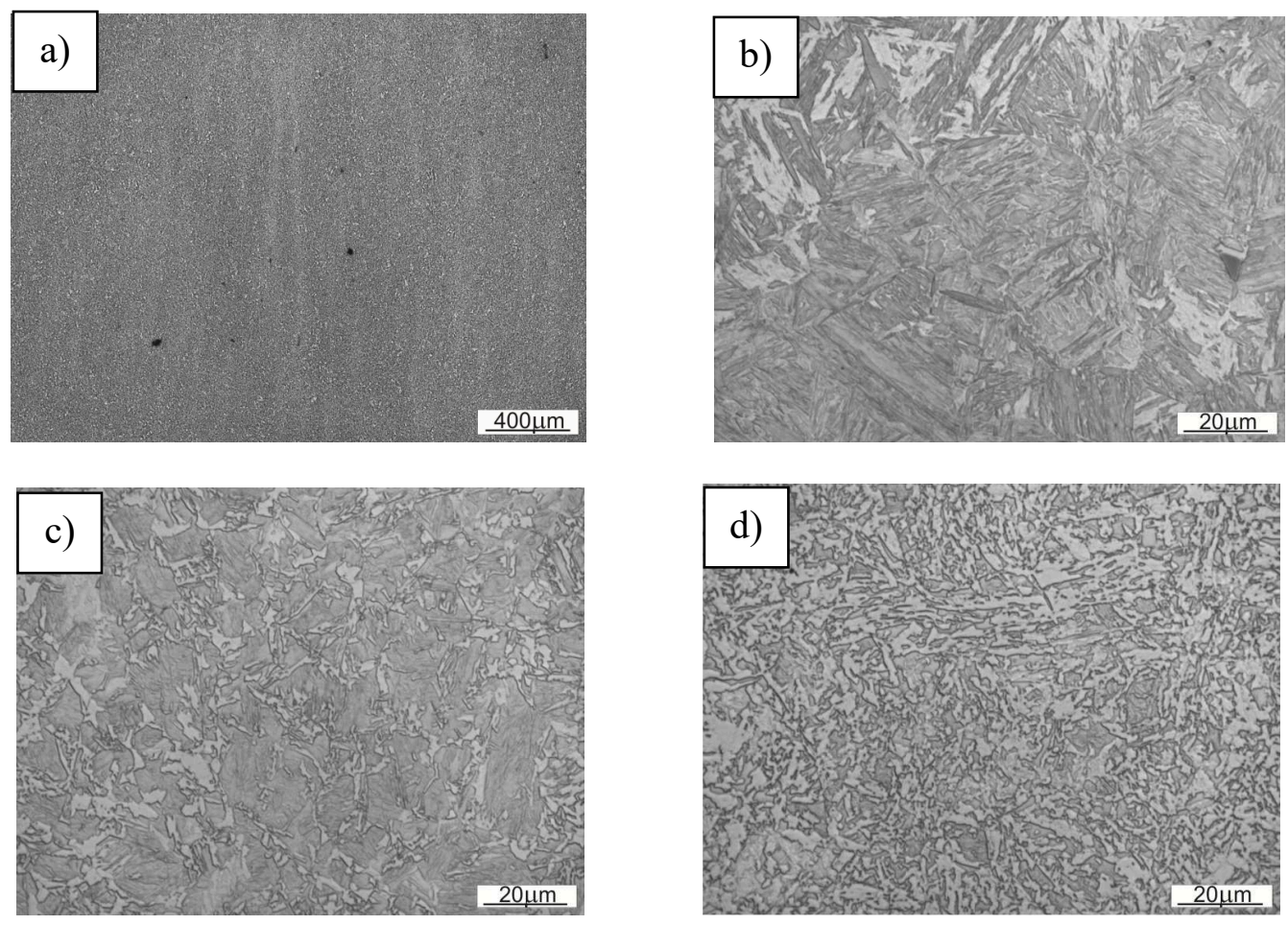

Fig. 4. The microstructure of chosen samples for MS steel cooled after rolling in 3 passes from finish rolling temperature in different media: $a, b$ ) water, c) water spray and d) air

Based on thermomechanical processing experiment it was found that all samples after deformation in three passes possess flowing bands in the sctructure, located longways to the rolling direction, Fig. 4a. The metallographic observation revealed that cooling of the sample from $890{ }^{\circ} \mathrm{C}$ to the ambient temperature in air allowed to obtain in steel structure ferrite and perlite, Fig. $4 \mathrm{~d}$. It was also observed that full martensite occur during cooling from finish rolling temperature in water, Fig. $4 \mathrm{~b}$ and bainitic-martensitic phase transformation products during cooling by water sprinkling, Fig. 4c. 

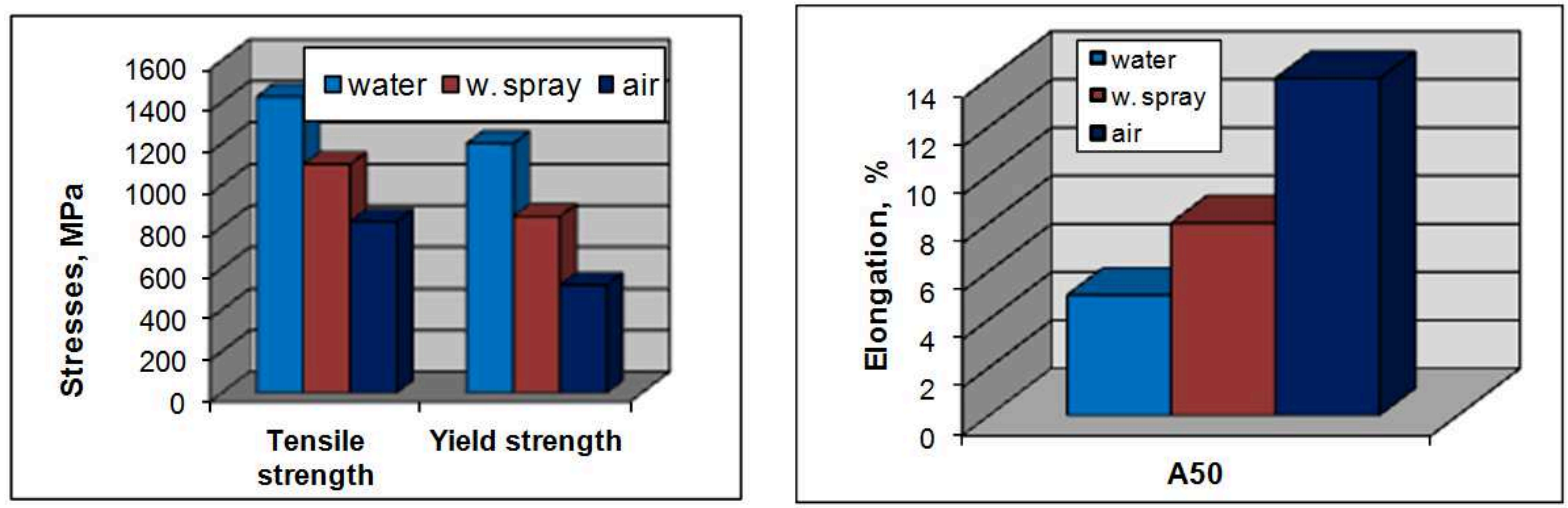

Fig. 5. Comparison of yield strength, tensile strength and elongation for strip samples rolled in three passes

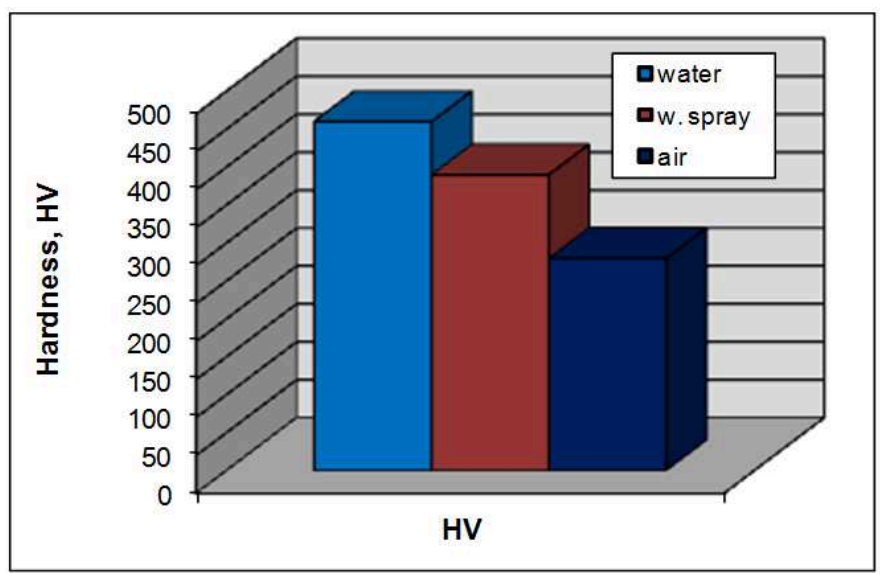

Fig. 6. Comparison of Vickers hardness for strip samples rolled in three passes

The structure of therommechnically rolled steel strips has an important role on their mechanical properties. The comparison of strength, plasticity and hardness properties after thermomechanically processed Martensitic Steel is shown in Fig. 5 and Fig. 6. The highest mechanical properties were obtained when water cooling directly after finish rolling temperature was applied. In this case hot rolled strips had microstructure containing $100 \%$ of lath martensite. The obtained microstructure has adequately high yield stress $\left(R_{e}=1200 \mathrm{MPa}\right)$ and high ultimate strength $\left(R_{m}=1425 \mathrm{MPa}\right)$ and low level of cold formability $\left(A_{50}=6 \%\right)$. By combining a number of different microstructures a wide range of mechanical properties of Martensitic Steel strips are possible for obtaining. For example using lower cooling rate after rolling higher formability can be achieved. Obtained results from thermomechanical rolling and cooling are well matching to the results from dilatometric test. To improve formability, the hot stamping process is proposed for this steel grade.

\section{Conclusions}

The results of investigations presented in the paper provide useful information for the designing of hot rolling and cooling of strips from Martensitic Steel. The obtained results also allow for formulating the more general conclusions:

1. The investigated Martensitic Steel characterizes very good tempering. This steel when quenched from finish rolling temperature with the cooling speed higher than $50{ }^{\circ} \mathrm{C} / \mathrm{s}$ possess structure fully martensitic.

2. The developed steel is suitable for rolling MS-type strips in the applied conditins of theromechanical processing. A proper selection of thermomechanical rolling conditions, eg. correct passes schedule, the rolling temperature range as well cooling rates, which avoid perlite and bainite transformstion allows to produce strips with martensite fraction. 
3. The applied conditions of controlled rolling and cooling can be useful by integrated technology lines by producing strips with martensitic structure after thermomechanical processing: $\mathrm{YS}_{0.2} \sim 1200 \mathrm{MPa}$, TS $\sim 1400 \mathrm{MPa}$ and UEl $\sim 6 \%$.

4. The different microstructures can be obtained by choosing hot rolling and cooling parameters, thus a wide range of mechanical properties of DP or CP steel strips can be acquired. This allows rolling mills to adjust process parameters to obtain the required properties.

\section{Acknowledgements}

Financial assistance of Polish Ministry of Science and Higher Education (AGH Project No.11.11.110.292) is acknowledged.

Special acknowledgment for Institute of Metal Forming at Technische Universität Bergakademie Freiberg for support in preparing plain strain compression tests by using Gleeble Simulator.

\section{References}

[1] Bleck W., Papaefthymiou S., Frehn A.: Microstructure and Tensile Properties in DP and TRIP Steels, Proc. of Conf. for Mechatronics, Patras, 2004, pp. 55-61.

[2] R. Kuziak, R. Kawalla, S. Wasngler, Advanced High Strength Steel for Automotive Industry, Archives of Civil and Mechanical Engineering, Vol. 8, No. 2 (2008), p.103-117.

[3] M. Dziedzic, S. Turczyn, Experimental and Numerical Investigation of Strip Rolling from Dual Phase Steel, Archives of Civil and Mechanical Engineering, Vol. 10, No. 4 (2010), p. 21-30.

[4] M. Dziedzic, S.Turczyn, Z. Kuźmiński, Designing of Hot Rolling and Cooling Conditions for Dual Phase and Complex Phase Steel Strip. Proc. of Metal 2015 Conf., 2015.

[5] M. Dziedzic, S. Turczyn, Rolling of Advanced High Strength Steels for Automotive Industry. In METAL 2012: $21^{\text {st }}$ International Conference on Metallurgy and Materials. Ostrava: TANGER, 2012.

[6] S. Keeler, M. Kimchi, Advanced High Strength Steel Application Guidelines - Version 5.0. WorldAutoSteel, May 2014 (online at www.worldautosteel.org). 